\title{
IDENTIFICATION OF DEGRADATION BY-PRODUCTS OF SELECTED PESTICIDES DURING OXIDATION AND CHLORINATION PROCESSES
}

\author{
IDENTYFIKACJA UBOCZNYCH PRODUKTÓW ROZKŁADU WYBRANYCH \\ PESTYCYDÓW W TRAKCIE PROCESÓW UTLENIANIA I CHLOROWANIA
}

\begin{abstract}
Advanced oxidation processes (AOPs) are considered to be one of the most effective methods for the decomposition of a wide range of hardly-biodegradable organic compounds, including pesticides. The implementation of such processes in the water streams treatment often leads to the formation of decomposition by-products of micropollutants occurring in water. These compounds, even in concentrations of a few $\mathrm{ng} / \mathrm{dm}^{3}$, may negatively affect the water quality. Therefore, there is a need for detailed analyses that will allow to identify intermediates found in the AOP solutions and to assess their impact on the aquatic environment. The paper presents an attempt to identify by-products of three pesticides: triclosan, triallat and oxadiazon during ozonation, chlorination and UV irradiation of their water solutions. The identification of compounds was performed based on the results of the GC-MS analysis using the NIST v17 mass spectral library. It has been shown that during all of tested advanced oxidation processes, incomplete degradation of pesticides occurs. The number of micropollutant decomposition by-products increases with the increase of the applied ozone dose and UV exposure time. During the chlorination process $\mathrm{Cl}^{-}$atoms were added to the tested compound molecules. In the case of triclosan, it led to the generation of compounds containing four or five chlorine atoms in their structure. The toxicological analysis performed by the use of the Microtox ${ }^{\circledR}$ and Lemna sp. Growth Inhibition Test showed the toxic nature of post-process solutions. The decomposition by-products of triclosan and triallate, generated during the UV irradiation process, were highly toxic against the test organisms (toxic effect $>75 \%$ ). This makes it impossible to drain these solutions into the natural environment.
\end{abstract}

Keywords: pesticides, by-products, ozonation, UV irradiation, chlorination

\section{Introduction}

Pesticides, as compounds used to control harmful or unwanted organisms, have a significant impact on the natural environment [1]. Particular attention should be paid to these compounds when monitoring the quality of water reservoirs. Pesticides belong to the group of persistent organic pollutants POPs, which are considered to be toxic and have a poor susceptibility to biodegradation [2]. The estimated number of pesticides and their metabolites available on the global market reaches 500 [3]. The concentration of these compounds in surface water depends on the location of the surface water (distance from

\footnotetext{
${ }^{1}$ Institute of Water and Wastewater Engineering, Silesian University of Technology, ul. S. Konarskiego 18, 44-100 Gliwice, Poland, phone +48 32237 2478, fax +48 3223710 47, email: edyta.kudlek@polsl.pl
} 
agricultural fields) and also on the soil characteristics, agricultural practices, topography, weather, and chemical properties of each pesticide compound [4]. According to the EU Drinking Water Directive [5] the total concertation of pesticides and their metabolites should not exceed $0.5 \mu \mathrm{g} / \mathrm{dm}^{3}$, however the average concentrations of pesticides in the water environment in Europe ranged from few ng to several $\mu \mathrm{g} / \mathrm{dm}^{3}$. Therefore, a constant increase in their presence in the aquatic environment has been demonstrated in numerous publications [6-8]. Climent et al. [9] pointed that the pesticide and their transformation products affects the quality of water bodies. Whereas Hernandez et al. [10] in a study dedicated to the assessment of the relevance of pesticides to human health, noted that even low-dose pesticide mixtures may have a long-lasting and negative health impact and can by the reason of cancer, neurodevelopmental deficits and the increase of chronic degenerative diseases. Therefore, reducing pesticide emissions into the natural environment becomes a priority topic in environmental protection.

Advanced oxidation processes allowed decomposition and obtaining high levels of removal of a wide range of hardly- or non-biodegradable organic compounds, including pesticides [3, 11]. The decomposition of compounds in these processes is a result of reactions with highly reactive free radicals such as non-selective hydroxyl radicals. Advanced oxidation processes can be implemented as single water treatment processes or they can be combined into sequential or hybrid systems. Hybrid systems have many advantages, including the ability to improve the efficiency of pollutants decomposition while reducing the time of water streams treatment. Commonly used methods of water disinfection, based on the action of chlorine, allow the decomposition of pesticides [12, 13]. However, the application of such processes often leads to the by-products formation and to an increase the toxicity of the treated water streams. Takanashi et al. [14] indicate that the chlorination of water containing pesticide residues result in the increase of water mutagenicity. Knowledge of particular stages of compound decomposition allows for the selection of optimal methods of their elimination from the environment, taking into account both environmental and economic aspects.

The aim of the performed research was to identify by-products of the decompocition of selected pesticides in the water environment formed during their exposure to UV irradiation, ozonation and chlorination. The tested pesticides belong to the grope of herbicides - triallate and oxadiazon, and fungicides - triclosan. Post-process solutions were subjected to toxicological analysis using the Microtox ${ }^{\circledR}$ and Lemna sp. Growth Inhibition Tests.

\section{Materials and methods}

\section{Pesticide water solutions}

Water solutions of selected pesticides: triallate, triclosan and oxadiazon constituted the subject of the study. The analytical standards of micropollutants of purity grade $>97.0 \%$ were supplied by Sigma-Aldrich (Poznan, Poland). Characteristics of the tested pesticides are presented in Table 1.

The solutions were prepared based on the deionized water witch a conductivity of $18 \mathrm{M} \Omega / \mathrm{cm}$ and dissolved oxygen concentration below $2.5 \mathrm{mg} / \mathrm{dm}^{3}$. The concentration of compounds in the tested solutions was set on $1000 \mu \mathrm{g} / \mathrm{dm}^{3}$. Therefore, it was necessary to use standard solutions especially in the case of oxadiazon, which is characterized by a weak solubility in water solutions (Table 1). Standard solutions were prepared by dissolving 
$10 \mathrm{mg}$ of each analyte in $10 \mathrm{~cm}^{3}$ of methanol. High concentrations of micropollutants that exceeded the usual environmental concentrations were applied in order to increase the accuracy of the analytical measurements. The $\mathrm{pH}$ of the prepared water solutions were adjusted to 7 using $0.1 \mathrm{~mol} / \mathrm{dm}^{3} \mathrm{NaOH}$ (purity grade $>99.6 \%$ ).

Characteristics of the tested pesticides [15]

Table 1

\begin{tabular}{|c|c|c|c|c|c|}
\hline Name & Use & CAS-RN & $\begin{array}{c}\text { Structural } \\
\text { formula }\end{array}$ & Molecular weight & $\begin{array}{c}\text { Solubility in } \mathbf{H}_{2} \mathbf{O} \\
{\left[\mathbf{m g} / \mathbf{d m}^{3}\right]}\end{array}$ \\
\hline triallate, TRI & herbicide & $2303-17-5$ & $\mathrm{C}_{10} \mathrm{H}_{16} \mathrm{Cl}_{3} \mathrm{NOS}$ & 304.65 & 2.00 \\
\hline triclosan, TCS & $\begin{array}{c}\text { fungicide, } \\
\text { bacteriostat }\end{array}$ & $3380-34-5$ & $\mathrm{C}_{12} \mathrm{H}_{7} \mathrm{Cl}_{3} \mathrm{O}_{2}$ & 289.54 & 10.00 \\
\hline oxadiazon, ODZ & herbicide & $19666-30-9$ & $\mathrm{C}_{15} \mathrm{H}_{18} \mathrm{Cl}_{2} \mathrm{~N}_{2} \mathrm{O}_{3}$ & 345.22 & 0.70 \\
\hline
\end{tabular}

Preliminary studies indicated that low concentrations of the used alkali do not affect the decomposition of the tested micropollutants before the implementation of treatment processes. The experiments for all tested compounds were carried out separately to identify decomposition by-products, which are the result of only oxidizing or chlorinating agents.

\section{Pesticide decomposition processes}

A glass batch reactor with a volume of $1.0 \mathrm{dm}^{3}$ was used for the implementation of the UV irradiation, ozonation and chlorination processes. To eliminate the influence of any kind of light on the reaction mixtures during the decomposition processes, the reactor was placed in a dark chamber. Therefore, the obtained results were the result only of the action of used oxidizing and chlorinating agents. The reactor was placed on a magnetic stirrer to ensure proper mixing of the reaction water solutions. All experiments were carried out in room temperature.

The UV irradiation was emitted by a medium-pressure mercury UV lamp model TQ 150 from Heraeus (Hanau, Germany). The lamp worked in a cooling jacket supplied with tap water, which protected the mixture from overheating. The radiation that emanated from the UV lamp, according to the data given by the producer Heraeus (Hanau, Germany), had a wavelength $\lambda_{\text {exc }}$ equal to $313,365,405,436,546$, and $578 \mathrm{~nm}$. The time of irradiation was set on $5,10,20,30,40$ and $60 \mathrm{~min}$.

$\mathrm{O}_{3}$ during the ozonation process was generated from fresh air by the use of an Ozoner FM500 ozone generator by WRC Multiozon (Sopot, Poland) and insert to the glass reactor by a ceramic diffuser. The $\mathrm{O}_{3}$ dose was set to $1.0,2.0,3.0,5.0$, and $10.0 \mathrm{mg} / \mathrm{dm}^{3}$. The $\mathrm{O}_{3}$ concentrations in the reaction mixture were measured photometrically using the Spectroquant $^{\circledR}$ Ozone Test by Merck KGaA (Darmstadt, Germany). The contact time between the oxidizing reagent and the prepared water solutions was estimated during preliminary studies [16] for $30 \mathrm{~min}$. $\mathrm{Na}_{2} \mathrm{SO}_{3}$ by Sigma-Aldrich (Poznan, Poland) at a dose of $24 \mathrm{mmol} / \mathrm{dm}^{3}$ was introduced into the reaction mixtures in order to stop the ozonation reaction.

The chlorination process was carried out by the use of $\mathrm{NaClO}$ with a nominal free chlorine content of $6 \%(\mathrm{w} / \mathrm{v})$. The used chlorine dose was equal to $0.5,1.0,1.5,2.0,2.5$ and $3.0 \mathrm{mg} / \mathrm{dm}^{3}$. The process was carried out $30 \mathrm{~min}$ and the chlorination reaction was stopped by removing the excess chlorine with $\mathrm{Na}_{2} \mathrm{~S}_{2} \mathrm{O}_{3}$ at a dose of $100 \mathrm{mg} / \mathrm{dm}^{3} . \mathrm{Na}_{2} \mathrm{~S}_{2} \mathrm{O}_{3}$ with a purity of $98.0 \%$ was purchased from Sigma-Aldrich (Poznan, Poland). $\mathrm{Na}_{2} \mathrm{~S}_{2} \mathrm{O}_{3}$ was introduced to the samples in the form of an aqueous solution. 


\section{Analytical procedure}

The concentration of pesticides in samples before and after the applied decomposition processes was estimated based on GC-MS chromatography with electron ionization preceded by solid phase extraction (SPE). Supelclean ${ }^{\mathrm{TM}}$ ENVI-18 disposable cartridges from Sigma-Aldrich (Poznan, Poland) were used for the SPE extraction. The column bed was polymerically bonded silica gel base material with $\mathrm{C}_{18}$ bonding. The conditioning procedure based on passing through the bed of acetonitrile and methanol (Avantor Performance Materials Poland S.A. (Gliwice, Poland)) and washing by deionized water. The volume of analysed water samples was equal to $20 \mathrm{~cm}^{3}$. The $\mathrm{pH}$ of each sample before was adjusted to 7.0. The analytes adsorbed on the column bed were eluted by $1.5 \mathrm{~cm}^{3}$ of methanol and the same volume of acetonitrile. Recovery of the tested pesticide compounds using the SPE procedure exceeded $98 \%$.

The 7890B GC-MS(EI) chromatograph by Perlan Technologies (Warszawa, Poland) was incorporated for pesticide and decomposition by-product determination. The chromatograph was equipped with a $\mathrm{SLB}^{\mathrm{TM}}-5 \mathrm{~ms} 30 \mathrm{~m} \times 0.25 \mathrm{~mm}$ capillary column of $0.25 \mu \mathrm{m}$ film thickness, obtained from Sigma-Aldrich (Poznan, Poland). The post-processed water samples after SPE extraction were analysed in the SIM (selected-ion monitoring) and TIC (total ion current) mode. Helium with a purity of $99.9 \%$ at a flow rate of $1.1 \mathrm{~cm}^{3} / \mathrm{min}$ was used as the carrier gas. Details of the SPE extraction and performed GC-MS analysis are given in the paper [17].

The percentage removal rate $R_{r}[\%]$ of each pesticide in post-processed solution was calculated according to equation (1), where $C_{i}$ and $C_{p}$ are the initial concentration (estimated in solutions before the subjection to decomposition processes) and post-processed compound concentrations $\left[\mathrm{mg} / \mathrm{dm}^{3}\right]$, respectively:

$$
R_{r}=\frac{C_{i}-C_{p}}{C_{i}} \cdot 100
$$

Assignment errors were estimated on the basis of the standard deviation for three repetitions of each test. The errors values for all tested samples did not exceed $2 \%$.

\section{Toxicity assessment}

The toxicological analysis was performed based on two biotest - Microtox ${ }^{\circledR}$ and Lemna sp. Growth Inhibition Test. The Microtox ${ }^{\circledR}$ test use lyophilized bioluminescent Aliivibrio fischeri bacteria as test organisms. It was conducted according the Screening Test procedure of the MicrotoxOmni system by the use of Microtox 500 analyser by Modern Water (Warszawa, Poland). The obtained result was expressed by the percentage of bioluminescence inhibition (toxic effect [\%]) caused by the inhibition of metabolic processes of indicator organisms subjected to a 5-minute exposure to the tested water samples. The estimated toxic effect of the tested sample is comparative to a reference nontoxic sample $(2.0 \% \mathrm{NaCl}$ solution).

Lemna minor vascular plants from own breeding was used during the Lemna sp. Growth Inhibition. The test was performed according to the OECD Guideline 221 in a temperature of $25 \pm 1^{\circ} \mathrm{C}$ by a constant exposure to 6000 lux light.

The effect of the toxicity $E$ [\%] expressed by visible morphological changes of plants was evaluated after 7 days as a percentage of inhibition of the growth of plant fronds according to formula (2), where $L_{c}$ and $L_{t}$ are the number of fronds for the control sample and the test sample respectively: 


$$
E=\frac{L_{c}-L_{t}}{L_{c}} \cdot 100
$$

Interpretation of the results was performed according to the toxicity classification presented in paper [16], which was prepared according to guidelines given by Mahugo Santana et al. [18].

\section{Results and discussion}

\section{Pesticide removal during decomposition processes}

Figure 1 presents the removal rates of tested pesticides in water solutions during the process of UV irradiation (Fig. 1a), ozonation (Fig. 1b) and chlorination (Fig. 1c).

a)

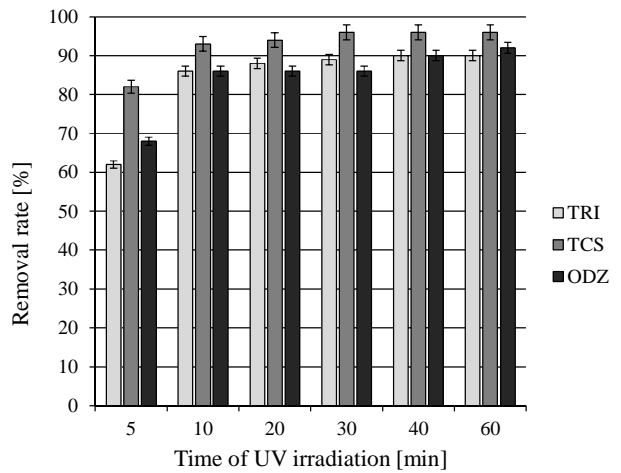

b)

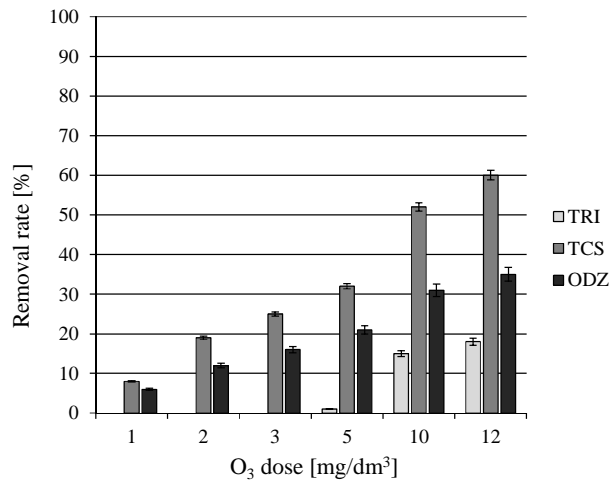

c)

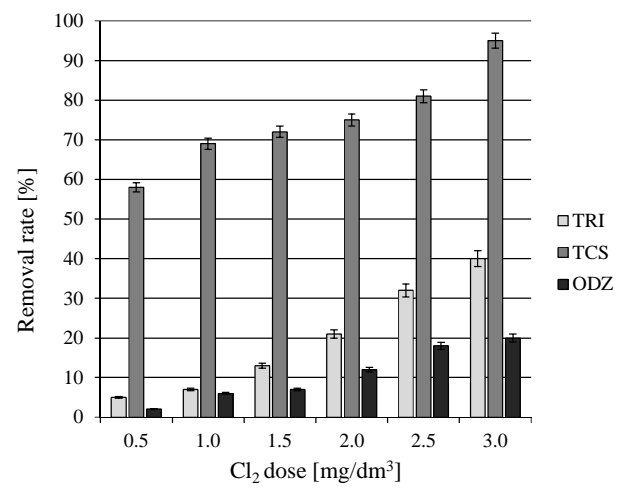

Fig. 1. The removal degrees of pesticides during the process of: a) UV irradiation, b) ozonation and c) chlorination

It has been observed, that the removal rate increases with the increase of the irradiation time and with the increase in the applied $\mathrm{O}_{3}$ or $\mathrm{Cl}_{2}$ dose. The highest decrease in compound concentration was noted for the UV based process. The implementation of UV light for 5 min resulted in an over $60 \%$ removal of triallate and oxadiazon and an over $80 \%$ decrease in the triclosan concentration. After $60 \mathrm{~min}$ of UV irradiation the triallate removal 
rate reached $90 \%$, while the oxadiazon concentration decreased by over $92 \%$ and the triclosan removal rate exceeded $96 \%$. A high triclosan removal rate reached $95 \%$ was also achieved during the chlorination process by the $\mathrm{Cl}_{2}$ concentration of $3 \mathrm{mg} / \mathrm{dm}^{3}$. Significant lower removal rates were noted for triallate and oxadiazon. The removal rates of these compounds was 40 and $20 \%$ respectively. The lowest effectiveness of pesticides decomposition was noted during ozonation. The introduction of $3 \mathrm{mg} / \mathrm{dm}^{3}$ of $\mathrm{O}_{3}$ to the tested solutions allowed only for a $25 \%$ decrease in triallate concentration and a $16 \%$ decrease in oxadiazon concentration. Whereas, for the $\mathrm{O}_{3}$ dose of $12 \mathrm{mg} / \mathrm{dm}^{3}$, a $60 \%$ removal of triclosan and a $35 \%$ removal of oxadiazon has been observed.

It can be summarized that the implementation of UV irradiation allows to achieve high micropollutant removal rates. Kumar Sharma [19] also noted that UV-based processes are effective methods for pesticide removal. However, the choice of the optimal source of radiation plays a significant role in this case. Gafar Muhamad [20] reported that the photodecomposition of pesticide water solutions exposed to UV-light is faster than in samples subjected to the direct sunlight or visible light.

\section{Pesticide removal during decomposition processes}

During the decomposition of compounds, bonds between particular atoms in the molecule are broken. Degradation pathways of compound can be theoretically predicted based on the knowledge of the bond dissociation energies theory. However, the identification of all theoretically defined compound decomposition by-products is impossible due to their different stability in the water environment.

Table 2

Summary of pesticide decomposition by-products

\begin{tabular}{|c|c|c|c|c|c|c|c|c|}
\hline \multirow{2}{*}{$\begin{array}{c}\text { Pesticide } \\
\text { water } \\
\text { solution } \\
\end{array}$} & \multirow{2}{*}{ Identified compound } & \multirow{2}{*}{$\begin{array}{c}\text { Similarity } \\
{[\%]}\end{array}$} & \multicolumn{3}{|c|}{ Process ${ }^{*}$} & \multirow{2}{*}{ CAS-RN } & \multirow{2}{*}{$\begin{array}{c}\text { Structural } \\
\text { formula }\end{array}$} & \multirow{2}{*}{$\begin{array}{l}\text { Molecular } \\
\text { weight }\end{array}$} \\
\hline & & & $\mathbf{U V}$ & $\mathbf{O}_{3}$ & $\mathrm{Cl}_{2}$ & & & \\
\hline \multirow{3}{*}{ triallat } & diallate & 99 & + & + & - & $2303-16-4$ & $\mathrm{C}_{10} \mathrm{H}_{17} \mathrm{Cl}_{2} \mathrm{NOS}$ & 270.22 \\
\hline & tetrachlorethylene & 85 & - & - & + & $127-18-4$ & $\mathrm{C}_{2} \mathrm{Cl}_{4}$ & 165.82 \\
\hline & N,N-diisopropylformamide & 90 & - & + & + & $2700-30-3$ & $\mathrm{C}_{7} \mathrm{H}_{15} \mathrm{NO}$ & 129.20 \\
\hline \multirow{4}{*}{ triclosan } & 2,3-dichlorophenol & 98 & - & + & + & $576-24-9$ & $\mathrm{C}_{6} \mathrm{H}_{4} \mathrm{Cl}_{2} \mathrm{O}$ & 163.00 \\
\hline & 4-chlorophenol & 98 & + & + & + & $106-48-9$ & $\mathrm{C}_{6} \mathrm{H}_{5} \mathrm{ClO}$ & 128.56 \\
\hline & $\begin{array}{c}\text { 2,3-dichloro-6-(2,4- } \\
\text { dichlorophenoxy)phenol }\end{array}$ & 92 & - & - & + & $63709-57-9$ & $\mathrm{C}_{12} \mathrm{H}_{6} \mathrm{Cl}_{4} \mathrm{O}_{2}$ & 323.98 \\
\hline & $\begin{array}{l}\text { 2,3,4-trichloro-6-(2,4- } \\
\text { dichlorophenoxy)phenol }\end{array}$ & 88 & - & - & + & 53555-01-4 & $\mathrm{C}_{12} \mathrm{H}_{5} \mathrm{Cl}_{5} \mathrm{O}_{2}$ & 358.42 \\
\hline \multirow{3}{*}{ oxadiazon } & $\begin{array}{l}\text { 5-tert-butyl-3-(2,4-dichloro- } \\
\text { 5-hydroxyphenyl)-1,3,4- } \\
\text { oxadiazol-2(3H)-one }\end{array}$ & 82 & + & + & - & $39807-19-7$ & $\mathrm{C}_{12} \mathrm{H}_{12} \mathrm{Cl}_{2} \mathrm{~N}_{2} \mathrm{O}_{3}$ & 303.14 \\
\hline & 4,6-dichlororesorcinol & 78 & - & + & + & $137-19-9$ & $\mathrm{C}_{6} \mathrm{H}_{4} \mathrm{Cl}_{2} \mathrm{O}_{2}$ & 178.00 \\
\hline & $\begin{array}{c}\text { 2,4-dichloro-1- } \\
\text { isopropoxybenzene }\end{array}$ & 96 & - & - & + & $6851-40-7$ & $\mathrm{C}_{9} \mathrm{H}_{10} \mathrm{Cl}_{2} \mathrm{O}$ & 205.08 \\
\hline
\end{tabular}

${ }^{*}+$ - compound present in post-process samples; - - compound absent in post-process samples

The examination of chromatograms obtained during analyses of post-processed samples conducted in the TIC mode (the ion recording mode ranged from 50 to $400 \mathrm{~m} / \mathrm{z}$ ) 
indicated the presence of several compounds, which did not occur in the pre-treated samples. Based on the mass spectra of the newly-formed intermediates and the NIST v17 database software, an attempt has been made to identify those compounds. Table 2 summarizes the decomposition by-products identified in particular pesticide decomposition processes.

The performance of the experiment on deionized water solution allows for the determination of by-product, which were formed only during the reactions between the decomposed compound and the radicals generated during each tested process.

The lowest number of pesticide decomposition by-products has been identified in samples after irradiation with UV light. In general the irradiation of water solutions with UV light lead to the direct homolysis of compounds or to the formation of $\mathrm{OH}^{*}$ radicals which react with the compound molecule. For example, during the photochemical decomposition of triallate, one atom of chlorine separates from the molecule, which results in the formation of diallate. This compound is also used as a pesticide and was classified by the Human Health Assessment Group in EPA's Office of Health and Environmental Assessment as a possible human carcinogen [21]. The UV irradiation of triclosan water samples leads to the formation of 4-chlorophenol and in the post-irradiated samples of oxadiazon 5-tert-butyl-3-(2,4-dichloro-5-hydroxyphenyl)-1,3,4-oxadiazol-2(3H)-one has been detected.

The ozonation process contributes to the formation of more intermediates than the UV-based process. During these process compound by-products were formed as a result of the effect of $\mathrm{O}_{3}$ itself and reactions with other reactive free radicals like: $\mathrm{HO}_{2}{ }^{\circ}, \mathrm{HO}_{3}{ }^{\circ}, \mathrm{HO}_{4}{ }^{\circ}$, $\mathrm{OH}^{\bullet} \mathrm{O}_{2}^{-\bullet}, \mathrm{O}_{3}^{-\cdot}$ [22]. After ozonation of water samples containing triallate, diallate and $\mathrm{N}, \mathrm{N}$-diisopropylformamide have been detected. The attack of $\mathrm{O}_{3}$ molecules on the bound occurring in oxadiazon have resulted in the formation of 5-tert-butyl-3-(2,4-dichloro-5hydroxyphenyl)-1,3,4-oxadiazol-2(3H)-one and 4,6-dichlororesorcinol.

Particular attention should be paid to the chlorination. During this process, compound with a larger number of $\mathrm{Cl}^{-}$atoms have been formed. For example, the chlorination of triclosan lead to the formation of 2,3-dichloro-6-(2,4-dichlorophenoxy)phenol with four $\mathrm{Cl}^{-}$ atoms and 2,3,4-trichloro-6-(2,4-dichlorophenoxy)phenol with five $\mathrm{Cl}^{-}$atoms in the compound structure.

\section{Toxicological analysis of post-process samples}

The next stage of the study was aimed at the assessment of the potential toxic character of pesticide water solutions before and after UV irradiation, ozonation and chlorination. The results marked in Figure 2 and 3 as " 0 " represent the toxicological evaluation of samples before the implementation of any decomposition process. Test performed by the use the Microtox ${ }^{\circledR}$ test with Aliivibrio fischeri bacteria as toxicity indicators, according to the four classes of solution toxicity, shows that only the triclosan water solution is defined as highly toxic (toxic effect $>75.0 \%$ ). The toxic effect of the remaining pesticide solutions was under $25 \%$ and they were classified as non-toxic.

During the UV irradiation process, an increase of the toxicity of both triallate and oxadiazon solutions with the increasing reaction time was observed. The oxadiazon solution after $60 \mathrm{~min}$ of UV irradiation become toxic (toxic effect $>50.0 \%$ ) while the triallate solution was highly toxic. The increase of the toxicity of the solution is related to the generated compound intermediates, which had a negative impact on the metabolism of 
indicator bacteria. It should be noted, that the $\mathrm{pH}$ of each sample was corrected before the test to an optimum range for the test organisms $(\mathrm{pH}=6.5)$.

An increase of the toxicity was also observed with the increase of the reagent dose during ozonation and chlorination. For example, triallate and oxadiazon solutions which react with $12 \mathrm{mg} / \mathrm{dm}_{3}$ of $\mathrm{O}_{3}$ became toxic to test organisms. However, water solutions of these two pesticides after the reaction with 2.5 and $3.0 \mathrm{mg} / \mathrm{dm}^{3}$ of $\mathrm{Cl}_{2}$ had a low toxicity (toxic effect $>25.0 \%$ ). Therefore, it can be assumed that the concentration of the formed by-products increased with the increase of the $\mathrm{O}_{3}$ and $\mathrm{Cl}_{2}$ dose. This observation was also confirmed during performed chromatographic analyses. For example the concentration of the triallat intermediate tetrachlorethylene was two times higher in samples treated with $3 \mathrm{mg} \mathrm{Cl}_{2} / \mathrm{dm}_{3}$ than in samples subjected to $1 \mathrm{mg} \mathrm{Cl} 2 / \mathrm{dm}^{3}$.

It was also noticed that the triclosan water solution was characterized by high toxicity regardless of the reagent dose and the implemented decomposition process.

It could be concluded, that the generated pesticide decomposition by-products are characterized by a higher toxicity against Aliivibrio fischeri bacteria than the initial compounds.

a)

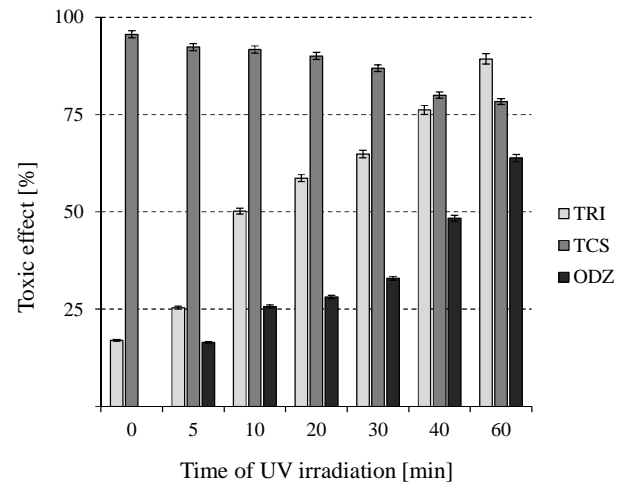

b)

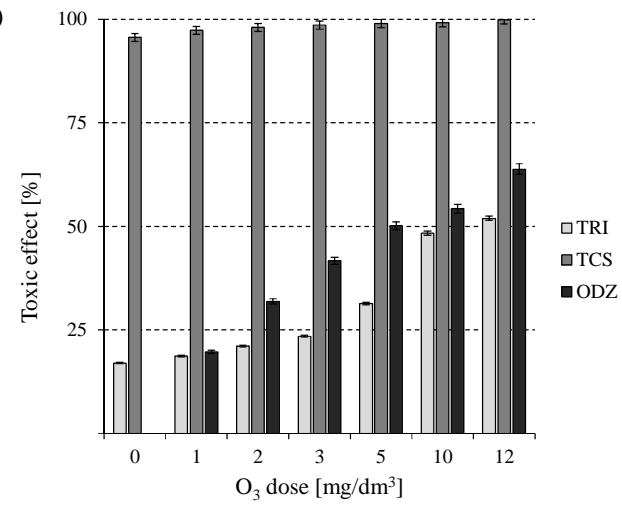

c)

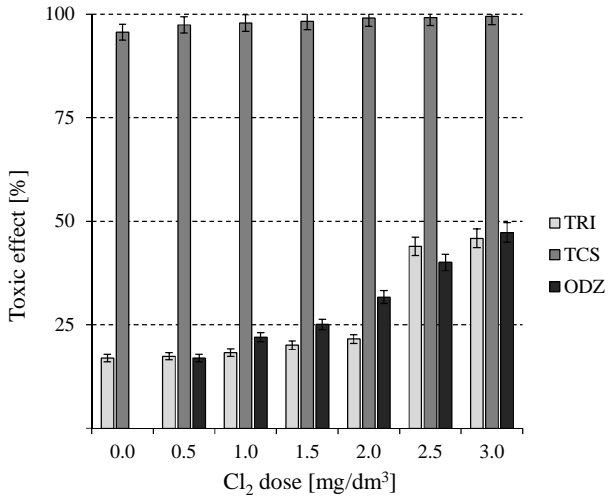

Fig. 2. Toxic effect observed in samples after: a) UV irradiation, b) ozonation and c) chlorination (Microtox ${ }^{\circledR}$ test) 
Differing results have been obtained during toxicity tests performed on vascular plants (Fig. 3). Test organisms have showed the highest sensitivity to the presence of oxadiazon in samples, which were not subjected to the decomposition processes. Oxadiazon not only inhibits plant growth, but also significantly affects the plant tissue leading to its necrosis (the observed toxic effect exceeded $83 \%$ ). The triclosan water solutions were characterized by the Lemna minor floating plant as toxic, while samples with triallate (as in the case of the Microtox ${ }^{\circledR}$ test) were non-toxic.

a)

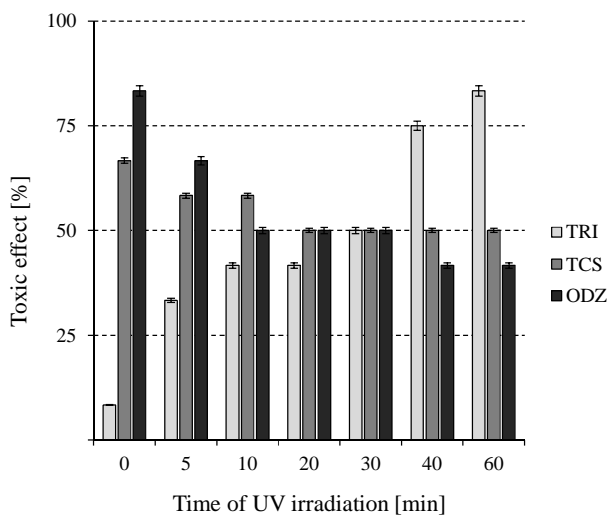

b)

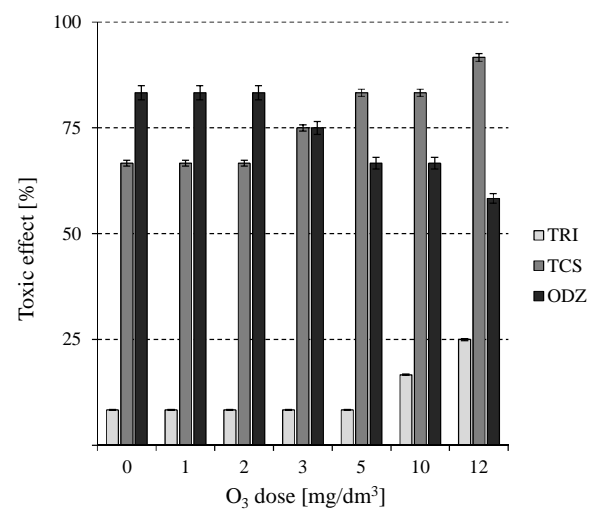

c)

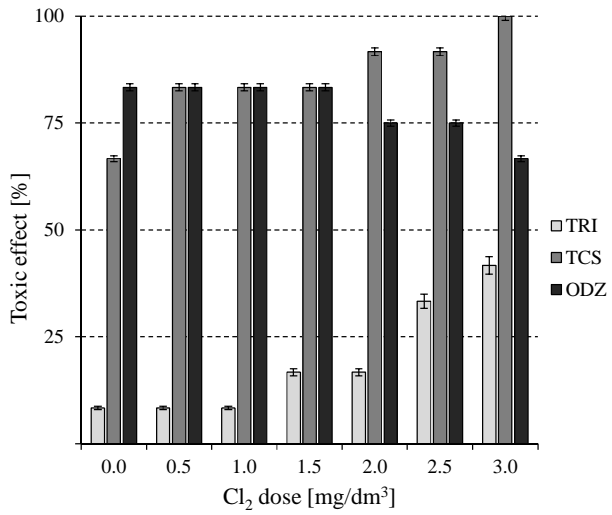

Fig. 3. Toxic effect observed in samples after: a) UV irradiation, b) ozonation and c) chlorination (Lemna sp. Growth Inhibition Test)

The toxicity of triclosan and oxadiazon samples subjected to UV irradiation decreased with the increase of the reaction time (Fig. 3a). Samples of both pesticides after a $30 \mathrm{~min}$ exposition to UV light were characterised by a low toxicity (toxic effect $<50.0 \%$ ). A decrease in the toxicity of oxadiazon water samples was also noted after the reaction with $\mathrm{O}_{3}$ and $\mathrm{Cl}_{2}$ (Fig. 3b and 3c). The toxicity of the oxadiazon samples decreased with the increase of the reagent dose, but this dependency was only noted for $\mathrm{O}_{3}$ doses ranged from 3.0 to $12.0 \mathrm{mg} / \mathrm{dm}^{3}$ and $\mathrm{Cl}_{2}$ doses from 2.0 to $3.0 \mathrm{mg} / \mathrm{dm}^{3}$. It can be concluded that oxadiazon is more harmful to the test plants then its intermediates. Therefore the decrease of its concentration leads to the decrease of the observed toxic effect. An inverse 
dependency was observed for triallate and triclosan solutions. The measured toxic effect increased with the increase of the used reagents. It should also be emphasized that the presence of diallate, which had been generated during the UV irradiation of triallate water samples, led to a significant increase of the toxicity effect measured by the use of vascular plants. Samples containing triallate and the generated diallate after $40 \mathrm{~min}$ of UV irradiation were classified as highly toxic (Fig. 3a). Likewise the formation of 2,3-dichlorophenol and 4-chlorophenol during the ozonation process of samples containing triclosan lead to the increase of the toxic effect against Lemna minor plants. However the highest toxicity level was noted for triclosan samples subjected to the chlorination process with $\mathrm{NaOCl}$ doses ranged from 2 to $3 \mathrm{mg} / \mathrm{dm}^{3}$. In those samples 2,3-dichloro6-(2,4-dichlorophenoxy)phenol and 2,3,4-trichloro-6-(2,4-dichlorophenoxy)phenol were determinate. Therefore it can be assumed that both intermediates have a harmful influence on floating plant indicators.

The obtained toxicity results indicated that the toxicity assessment gives not only information about the biological effect of the tested samples, but may also serve as an indirect assessment of the formation of decomposition intermediates of the tested compounds.

\section{Conclusions}

- Among the tested pesticide decomposition processes the process of UV irradiation was characterised by the highest efficiency in the reduction of the concentration of individual compound (removal rate $>90 \%$ ).

- With the increase of the reagent dose during both ozonation and chlorination processes an increase in the pesticide removal rate was noted.

- During the decomposition of micropollutants several by-products were formed. These product can still act as pesticides or be biologically active in other ways.

- The chlorination of compounds leads to the generation of intermediates with a larger number of $\mathrm{Cl}^{-}$atoms in their structure then in the structure of the parent compound.

- Toxicological tests can serve as an indirect assessment of the formation of decomposition intermediates, but they have a different sensitivity to the tested toxicants and their decomposition by-products. The highest toxic potential was noted for triclosan water solutions regardless of the applied decomposition method and the performed toxicity test.

\section{Acknowledgment}

This work was supported by Ministry of Science and Higher Education Republic of Poland within statutory funds No. 08/040/BKM-19/0118.

\section{References}

[1] Sun R, Luo X, Li QX, Wang T, Zheng X, Peng P, et al. Sci Total Environ. 2018;616-617:38-45. DOI: 10.1016/j.scitotenv.2017.10.296.

[2] Tijani JO, Fatoba OO, Madzivire G, Petrik LF. Water Air Soil Pollut. 2014;225:2102. DOI: $10.1007 / \mathrm{s} 11270-014-2102-\mathrm{y}$.

[3] Reddy PVL, Kim K-H. J Hazard Mater. 2015;285:325-335. DOI: 10.1016/j.jhazmat.2014.11.036.

[4] Hossain MS, Alamgir Zaman Chowdhury M, Kamruzzaman Pramanik Md, Rahman MA, Fakhruddin ANM, Khorshed Alam M. Appl Water Sci. 2015;5:171-179. DOI: 10.1007/s13201-014-0178-6. 
[5] Council Directive 98/83/EC of 3 November 1998 on the quality of water intended for human consumption. OJ L 330 5.12.1998:32. http://data.europa.eu/eli/dir/1998/83/2015-10-27.

[6] Albuquerque AF, Ribeiro JS, Kummrow F, Nogueira AJ, Montagner CC, Umbuzeiro GA. Environ Sci Process Impacts. 2016;18:779-787. DOI: 10.1039/c6em00268d.

[7] Székács A, Mörtl M, Darvas B. J Chem. 2015:1-15. DOI: 10.1155/2015/717948.

[8] El Alfy M, Faraj T. Environ Geochem Health. 2017;39:231-253. DOI: 10.1007/s10653-016-9825-1.

[9] Climent MJ, Herrero-Hernández E, Sánchez-Martín MJ, Rodríguez-Cruz MS, Pedreros P, Urrutia R. Environ Pollut. 2019;251:90-101. DOI: 10.1016/j.envpol.2019.04.117.

[10] Hernández AF, Parrón T, Tsatsakis AM, Requena M, Alarcón R, López-Guarnido O. Toxicology. 2013;307:136-145. DOI: 10.1016/j.tox.2012.06.009.

[11] Oturan MA, Aaron J-J. Crit Rev Environ Sci Technol. 2014;44:2577-2641. DOI: 10.1080/10643389.2013.829765.

[12] Rahman M, Kim TH, Kwon GS, Yang JE, Park M, Kim J-E. J Korean Soc. Appl. Biol Chem. 2009;52:252-257. DOI: 10.3839/jksabc.2009.045.

[13] Canosa P, Morales S, Rodríguez I, Rubí E, Cela R, Gómez M. Anal Bioanal Chem. 2005;383:1119-1126. DOI: $10.1007 / \mathrm{s} 00216-005-0116-4$.

[14] Takanashi H, Hama T, Nakajima T, Ohki A, Kondo T, Kameya T, et al. J Water Environ Technol. 2014;12:25-32. DOI: 10.2965/jwet.2014.25.

[15] Kim S, Thiessen PA, Bolton EE, Chen J, Fu G, Gindulyte A, et al. Nucleic Acids Res. 2016;4:D1202-D1213. DOI: 10.1093/nar/gkv951.

[16] Kudlek E, Dudziak M. Desalin Water Treat. 2018;117:88-100. DOI: 10.5004/dwt.2018.22096.

[17] Kudlek E. Water. 2018;10:955. DOI: 10.3390/w10070955.

[18] Mahugo Santana C, Sosa Ferrera Z, Torres Padron ME, Santana Rodríguez JJ. Molecules. 2009;14:298-320. DOI: 10.3390/molecules14010298.

[19] Kumar Sharma A, Kumar Tiwari R, Singh Gaur M. Arabian J Chem. 2016;9:S1755-S1764. DOI: 10.1016/j.arabjc.2012.04.044.

[20] Gafar Muhamad S. Arabian J Chem. 2010;3(2):127-133. DOI: 10.1016/j.arabjc.2010.02.009.

[21] U.S. National Library of Medicine, TOXNET Toxicology Data Network. https://toxnet.nlm.nih.gov/ cgi-bin/sis/search2/r?dbs+hsdb:@term+@rn+@rel+2303-16-4.

[22] Jin X, Peldszus S, Huck PM. Water Res. 2012;46:6519-6530. DOI: 10.1016/j.watres.2012.09.026. 